\title{
Nutrition in schools:
}

Whose responsibility?

\section{Sarah Gray}

\section{Introduction}

T $t$ is not uncommon to find educational literature that L links poor nutrition to lowered performance on school related tasks and to a variety of behavioural and wellness concerns. Media speaks consistently to the issue of Canadian children who arrive at school either underfed or poorly fed. Nutrition experts refer to what is contained in many lunch bags, or what foods children consume as snacks, as not meeting Canada's Food Guide recommendations. Food served in school cafeterias is often described as less than adequate. Even if children are provided with a proper breakfast and a healthy lunch often they refuse to eat what is provided and supplement with junk food options. To add fuel to the fire, prior to October 2004, elementary school children were able to purchase junk food through vending machines at school. With the passing of significant legislation by the Ontario government, that is no longer the case. However, while vendors are obliged to provide better nutritional choices it does little to alleviate the problem that many school children arrive at school either underfed or not fed at all.

\section{A question}

As a prospective teacher I am concerned about whose responsibility it is to educate children about nutrition? More specifically, I ask, at what point is it a school boards' responsibility to ensure that all children receive a nutritious start to the school day?
It may not be well known that "Nutrition" is a compulsory aspect of the curriculum for Ontario students enrolled in kindergarten to grade eight. And, while there are courses offered at some secondary schools about nutrition, it is not compulsory beyond grade nine(Ontario Ministry of Health, www.edu.gov.on.ca/eng/document/curricul/seccurric.html). A study by Cullen, K.W., Eagan, J. and others (2000) reported that by providing better food choices for students and explaining why they are important, student consumers regulated their own choices and easily made the transition from junk food to appropriate snack food. The Ottawa Centre for Research and Innovation (2004) showed that students who have a nutritious breakfast tend to be more alert, have a positive sense of self esteem, participate in school activities more eagerly, exhibit less discipline problems and do better academically. Cruikshank (2005), showed that schools which participate in breakfast programs, snack supplement programs and other types of partnership food programs have been successful in decreasing student behaviour problems in school. There appears to be a direct link to eating right and behaving right.

Responding to the research and in partnership with a variety of nutrition experts, school boards across Canada are beginning to implement breakfast and snack food programs and put in place policies designed to enhance the nutritional value of foods purchased in school cafeterias and vending machines (for additional information, conduct a Web search under Canada School Boards/nutrition/programs/breakfast programs). For instance, many schools within the jurisdiction of school boards that comprise the Golden Horseshoe Educational Consortium group participate in community led breakfast programs guided by the Canada Food Guide, Choices 4 Health, the Food For Thought program and a modified Eat Smart (Restaurant) Program. The Halton District Catholic and Public school boards operate a snack program that provides all students with a nutritious break. Many schools have adopted the Menu of Choices program created by the Ontario Physical and Health Education Association and refer to the Ministry of Children and Youth Services (2005) set of "Nutrition" guidelines designed to assist schools interested in enchancing the nutritional quality of life of students.

\section{Answering my own question}

Based on what I have discovered and learned, it would seem that teachers have an opportunity to influence a student's nutrition choices inside and outside the classroom. Students may observe a teacher drinking a soft drink or eating a bag of potato chips while walking through the hall. Although these actions may be unintentional and deemed harmless, it reinforces unhealthy eating behaviours in the minds of students. Along with this, teachers often reward their students with treats such as candy or pizza. If healthier rewards were given to students, such as fruits and vegetables, students may begin to see the healthy food as a treat and snack on these healthier options instead of junk food. A growing number of 


\section{TEACHING \& LEARNING}

public health organizations and action groups are increasing involvement in the nutrition of students. Choice 4 Health, a partnership of public health and community dietitions and other health and community representatives, encourages teachers to practice what they teach. They advocate that schools avoid selling chocolate for fund-raising purposes and, instead, sell healthier options such as fruits or non-food items including cookbooks. They provide resources to assist teachers in planning healthy pizza and sandwich days (Choices4 Health, 2004) and will assist in the education of volunteers who work in breakfast and snack programs and will help plan meals for school cafeterias.

It seems appropriate that a school board should have a say in the type of food prepared and served by the food services in their cafeterias and should be responsible for ensuring that school catering agencies provide planned offerings that are nutritious and follow Canada's Food Guide recommendations. Unfortunately, it seems that in many schools, the meals and snacks do not conform to the food guide recommendations. High fat, and deep fried foods and high calorie snacks win over more nutritious vegetables and fruit as the former are big money makers for the catering companies. The result is that often students do not have many healthy food options. There are those that suggest that school boards should mandate elimination of all junk food and unhealthy snacks in school cafeterias and vending machines, and that students should be encouraged to choose healthier foods by providing options that satisfy their nutritional needs and taste standards.

It is obvious that the solution to student's nutrition is a multifaceted approach that involves cooperation and collaboration. Parents, educators, food service staff, health workers, dietitians and nutritionists alike all need to work together to bring about changes to the way children and teens perceive healthy food choices. In addition, school boards must constantly work with food suppliers to ensure that cafeterias and food supplement programs provide healthy and nutritional food choices. As well, I am convinced that school boards have a responsibility to work with community agencies and volunteer groups to provide breakfast and perhaps lunch programs when necessary, and to enhance student nutrition through free supplementary snack and nutrition breaks.

Parents are the first source of nutrition education for students and remain role models for them throughout their lives. The information taught to students at school is only effective if the actions are reinforced inside and outside the classroom as well as in the home. Parents and schools have to work as a team to help students make the correct food choices and move towards a healthier future. Teachers are encouraged to invite school officials to adopt and implement the variety of assistance that is available to ensure that students are provided with the right choices, even if it might be "only while they are in school."

\section{References}

Bongers, Agnes \& Brellisford. (2004). Nourishing Body And Mind. Retrieved September 15, 2005, from http:// www.hwdsb.on.ca/about_us/news$\mathrm{r}$ o $\mathrm{o} \mathrm{m} / \mathrm{v}-2-0-1 /$ news_detail.aspx?newsid $=285$

Central Okanagan District School Board, Healthy choices Ad Hoc Committee (2004). Guidelines for Food Choices in School Stores \& Vending Machines.

\section{3:1 Winter 2005}

Retrieved September 13, 2005, from http://www.dashbc.org/resources/ central_okanagan.pdf

Choices 4 Health. (2004). Schools: Healthy Eating. Retrieved September 19, 2005, from http:// www.choices 4 health.org/ index.cfm?fuseaction=Schools. EatSchool

Cruikshank, Gayle. Telephone Interview. 22 October 2005.

Cullen KW, Eagan, J., Baranowski T., Owens, E., \& Moor C.D. (2000). Effects of a la carte and snack bar foods in school on children's lunchtime intake of fruits and vegetables. Journal of American Dietetic Association, 100, 1482-1486.

Healthy Living Niagara. (2005). Eat Smart! School Cafeteria Program. Retrieved October 19, 2005, from http:// www.healthylivingniagara.com/.

Ottawa Centre for Research and Innovation. (2004) School Breakfast Program. Retrieved September 15, 2005, from http:// www.ottawaschoolbreakfastprogram.ca/ faq2.asp.

The Region of Waterloo Public Health. (2005). School Nutrition. Retrieved September 14, 2005, from http:// chd.region.waterloo.on.ca/web/ health.nsf/0/3831BD889D28097A8 5256F97006A15DF?OpenDocument.

Sarah Gray is a recent graduate of McMaster University with an

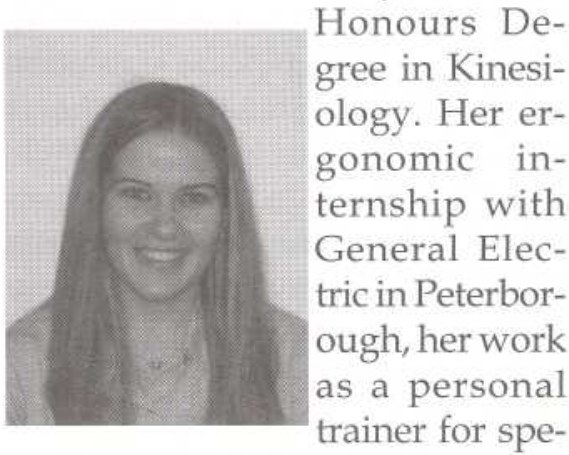
cial populations and her undergraduate program has shaped her interest in nutrition and wellness. Sarah is currently enrolled in Brock's Pre-Service Teacher Education as a teacher candidate for Intermediate/Senior Physical Education and Chemistry. 